Paper No. 38

\title{
A MODEL FOR THE MICROWAVE EMISSIVITY OF THE OCEAN'S SURFACE AS A FUNCTION OF WIND SPEED
}

\author{
Thomas T. Wilheit, Greenbelt, Maryland
}

\begin{abstract}
A quantitative model is presented which describes the ocean surface as an ensemble of flat facets with slopes distributed as per Cox and Munk (1955) partially covered with an absorbing nonpolarized foam layer. Experimental evidence is presented for this model.
\end{abstract}

\section{INTRODUCTION}

The launch in 1978 of the Scanning Multichannel Microwave Radiometer (SMMR) on both the Nimbus-7 and Seasat satellites has opened new possibilities for measurement of many geophysical observables, primarily the wind speed and water temperature at the ocean surface. Since the microwave brightness temperature observed in each of the SMMR channels is significantly affected by at least four variables, the liquid and vapor components of atmospheric water, sea surface temperature and surface wind, retrieval of the surface parameters is a non-trivial problem. The weak point in the physical understanding of these effects is in the effect of wind on the sea surface. Hopefully, the model presented here improves the situation somewhat. The model is clearly imperfect, but hopefully, will provide a framework and reference point for future refinements.

There have been two closely related programs supported by the Global Weather and GARP programs. The improved modeling of the microwave emissivity of the ocean surface, here reported, has been supported by Global Weather and is the key physical input to the algorithm for the retrieval of wind speed and sea surface temperature developed under the GARP Program. The approach taken here will be to present the model then to discuss several supporting observations.

\section{THE MODEL}

It is a straightforward problem to calculate the emissivity of a smooth water surface. The dielectric properties of sea water and saline solutions have been discussed by many authors. (Lane and Saxton (1952), Klein and Swift (1977), and Stogryn (1971)). We will use values derived from the Lane and Saxton (1952) measurements and expressed in an analytic form by Chang and Wilheit (1978). The formalism for calculating the emissivity for a given view angle and polarization is the so called Fresnel relations (Jackson 1962). The resulting emissivity as a function of view angle is shown in Figure 1 for a frequency of $10.7 \mathrm{GHz}$ and a temperature of $285^{\circ} \mathrm{K}$. Unfortunately, the ocean's surface is not a smooth surface; the wind roughens the surface, and, if it is blowing hard enough, partially covers the surface with foam. Cox and Munk (1955) have quantitatively described the distribution of surface slopes as a function of wind speed. They found that the 


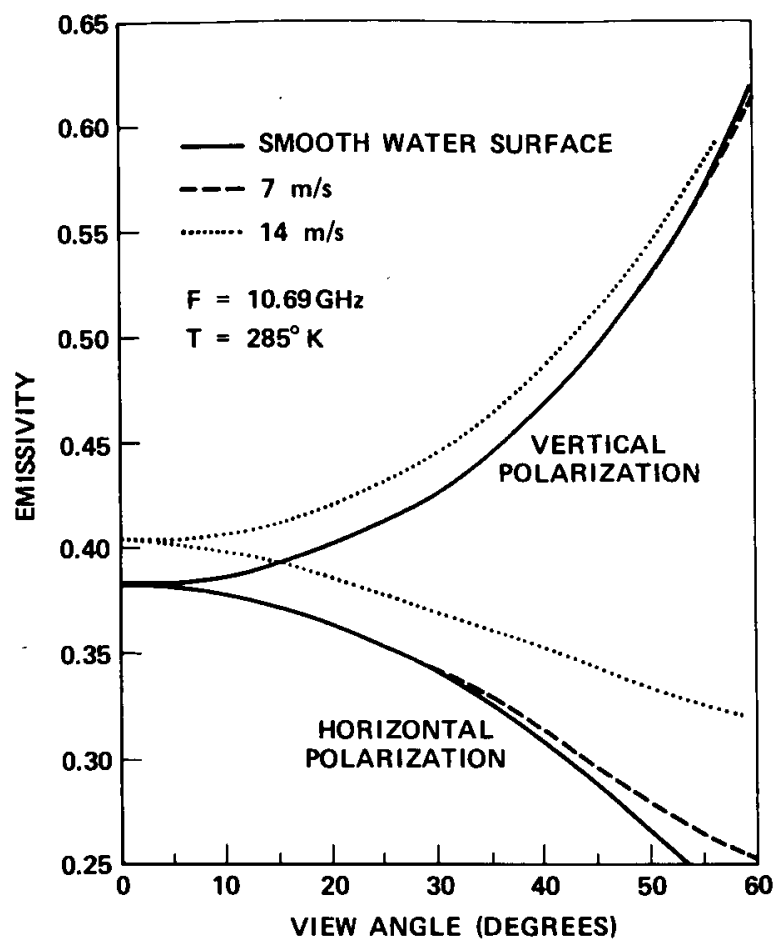

Fig. 1-Emissivity as a function of view angle for a smooth water surface and for the ocean surface with 7 and $14 \mathrm{~m} / \mathrm{s}$ wind speed.

surface slopes were normally distributed with a variance, $\sigma_{\mathrm{cm}}^{2}$, given by $\sigma^{2}=.003$ $+.0048 \mathrm{~W}$ where $\mathrm{W}$ is the wind speed in meters/second at $20 \mathrm{~m}$ height. The factor multiplying $\mathrm{W}$ in the above equation is slightly different from that in the Cox and Munk (1955) paper because the winds were measured at $12.5 \mathrm{M}$ in their work; the conversion to $20 \mathrm{~m}$ was done using the Cardone (1969) model for the atmospheric boundary layer assuming neutral stability.

The Cox and Munk (1955) measurements were made at visible wavelengths. Much of the roughness they observe is at scales very small compared to microwave wavelengths. This model requires only a fraction of the Cox and Munk roughness at the longer microwave wavelengths. Specifically, the slope variance observed at a given microwave frequency is:

$$
\begin{gathered}
\sigma^{2}(\mathrm{f})=(0.3+0.02 \mathrm{f}(\mathrm{GHz})) \sigma_{\mathrm{cm}}^{2} \quad f<35 \mathrm{GHz} \\
\sigma^{2}(\mathrm{f})=\sigma_{\mathrm{cm}}^{2} \quad \mathrm{f} \geqslant 35 \mathrm{GHz}
\end{gathered}
$$

To calculate a rough surface emissivity from this slope distribution, one simply averages the Fresnel relations (Jackson 1962) over the distribution of surface slopes. In doing so, one implicitly ignores surface curvature and all structure comparable to a wavelength and thereby reduces the problem to geometric optics. The 
comparison with observations which follow will demonstrate that this is a surprisingly good approximation.

Wind also creates foam on the ocean's surface. Nordberg et al (1971) found a linear increase in brightness temperature with wind speed whenever the wind speed exceeded $7 \mathrm{~m} / \mathrm{s}$. They were viewing directly at the nadir which essentially eliminates the roughness effect leaving foam as the most reasonable explanation. In our model, we will treat foam as partially obscuring the surface in a manner independent of polarization. A non-reflecting material partially covering the surface would have this property as would an absorbing but partially transparent medium with the same temperature as the water. Either description alone would be inadequate, but a combination of the two descriptions would be closer to reality. The degree to which foam obscures the surface is frequency dependent and proportional to the amount by which the wind speed exceeds $7 \mathrm{~m} / \mathrm{s}$. A reasonable approximation to the available observations of the fraction, $K$, by which the surface reflectivity is reduced by foam is

$$
\mathrm{K} \cong \mathrm{a}\left(1-\mathrm{e}^{-\mathrm{f} / \mathrm{fo}}\right)(\mathrm{W}-7 \mathrm{~m} / \mathrm{s})
$$

where $f$ is the frequency

and $\mathrm{a}=.006 \mathrm{~s} / \mathrm{m}$

$$
\mathrm{f}_{0}=7.5 \mathrm{GHz}
$$

The primary available observations relevant to this are from the Bering Sea Expedition (BESEX) (Webster et al 1976) and from Cosmos 243 (Shutko 1978). These results, along with a plot of $\partial \mathrm{K} / \partial \mathrm{W}$ is given in Figure 2. The observations are difficult but nevertheless show reasonable self-consistency except possibly for the one BESEX point at $37 \mathrm{GHz}$.

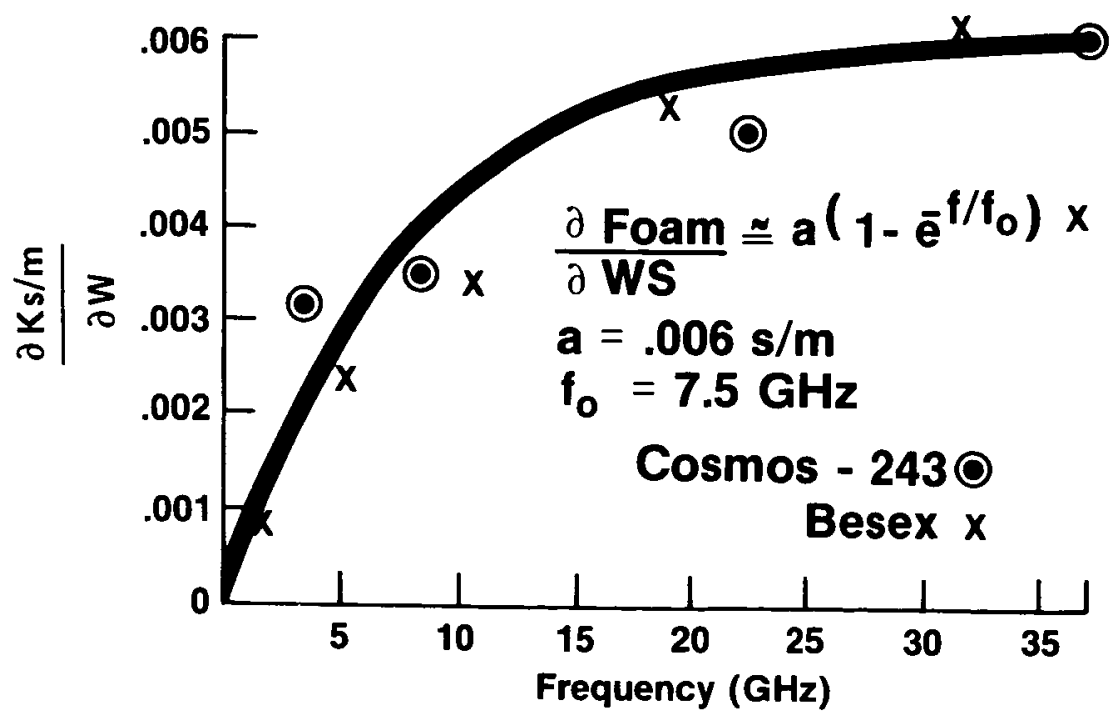

Fig. 2-Frequency dependence of reduction of reflectivity by foam. 
Emissivities calculated according to this model for 7 and $14 \mathrm{~m} / \mathrm{s}$ are shown in Figure 1 for comparison with the emissivity of a smooth surface:

\section{SUPPORTING OBSERVATIONS}

Because the assumed foam model has no polarization character, dual polarized observations of the surface provide a test of the rough surface portion of the model. If one makes the approximation that the atmosphere and the surface have the same thermodynamic temperature $T_{1}$, then it is straightforward to show that for any given view angle

$$
\mathrm{F}_{\mathrm{T}_{1}}(\theta)=\frac{\mathrm{T}_{\mathrm{H}}(\theta)-\mathrm{T}_{1}}{\mathrm{~T}_{\mathrm{V}}(\theta)-\mathrm{T}_{1}}=\frac{\mathrm{R}_{\mathrm{H}}(\theta)}{\mathrm{R}_{\mathrm{V}}(\theta)}
$$

Here $T_{H}(\theta)$ is the horizontal brightness temperature at an angle $\theta$ and $R_{H}(\theta)$ is the horizontally polarized reflectivity. $T_{V}(\theta)$ and $R_{V}(\theta)$ refer similarly to vertical polarization. Note that because $F_{T_{1}}(\theta)$ is the ratio of two reflectivities, it is independent of foam cover and thus provides a measurement of surface roughening. The data from the Electrically Scanned Microwave Radiometer (ESMR) on Nimbus-6 $\left(37 \mathrm{GHz}, 50^{\circ}\right.$ view angle) have been so analyzed and compared with wind speeds derived from the operational data buoys (Wilheit, 1978). A summary of this comparison is given in Figure 3. The plotted data are for the most part, averages of

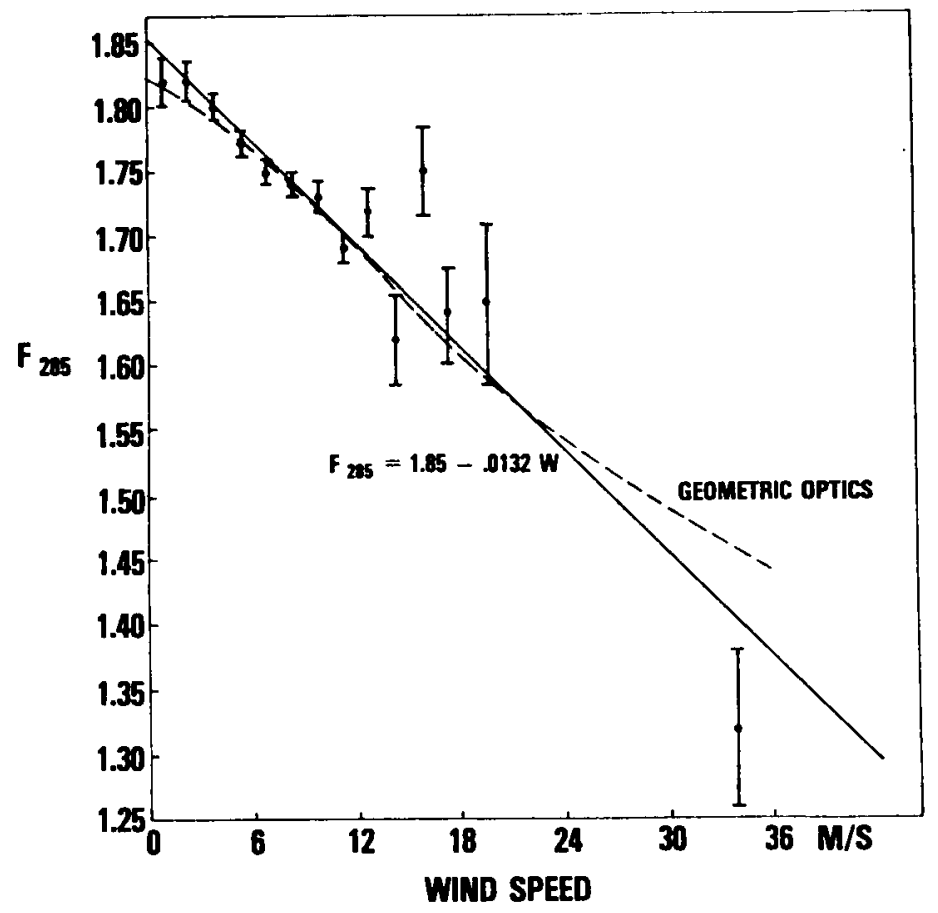

Fig. 3-Comparison between observed values of $F_{285}$ and wind speed averaged over $1.5 \mathrm{~m} / \mathrm{s}$ intervals. 
many observations; a total of 264 observations are represented. In analyzing the data, it was found that a value of $285^{\circ} \mathrm{K}$ for $\mathrm{T}_{1}$ worked best but that the improvement over any value in the range $280^{\circ} \mathrm{K}$ to $290^{\circ} \mathrm{K}$ was only marginal. Using the model described in the previous section the expected value of $F_{285}$ has been calculated; the agreement with the observations is striking. A geometric optics model using the Cox and Munk sea surface slope distribution works extremely well at a wavelength of $0.8 \mathrm{~cm}$ and a view angle of $50^{\circ}$. Hollinger (1971) has made observations from a fixed platform at frequencies of $1.4,8.36$, and $19.34 \mathrm{GHz}$. He has filtered the data to remove most of the foam effect but application of an analysis technique similar to that applied to the Ninibus-6 ESMR data certainly removes the remainder. These data all can be interpreted in terms of the geometric optics model but with much less slope variance than the Cox and Munk values.

The fractions of the Cox and Munk slope variance required to account for the Hollinger data are plotted in Figure 4 along with the Nimbus-6 ESMR observation. These data form a picture consistent with the roughness required in our model (shown as a solid line).

\section{CONCLUSION}

A model has been presented for the microwave emissivity of a wind roughened, foam covered ocean. The roughness portion of the description is remarkably consistent with observations; the foam effects show somewhat more scatter. The strength of the foam cover effect at 6.6 and $10.7 \mathrm{GHz}$ are important parameters in the interpretation of Nimbus-7 and Seasat SMMR data; the strength at higher frequencies, less so. In comparing the space observations with surface measurements of temperature and wind speed, it should be possible to adjust the foam effect at these two frequencies in order to fine-tune the retrieval algorithm.

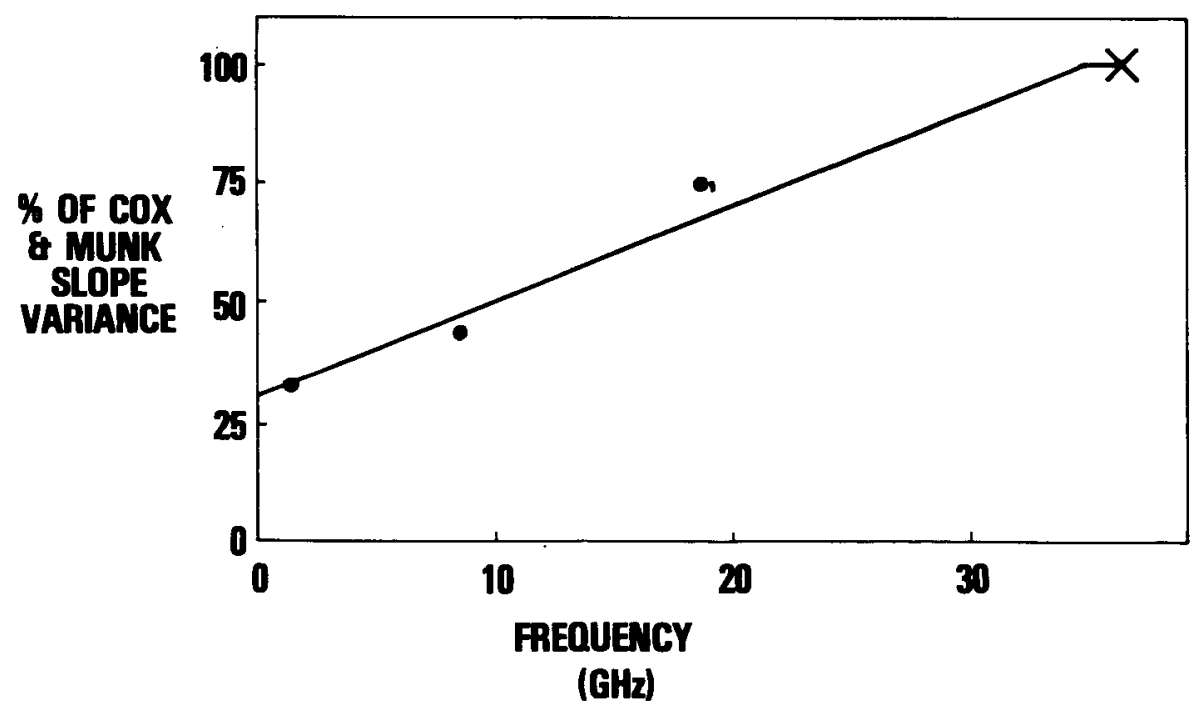

Fig. 4-Percentage of Cox and Munk (1955) slope variance required for a geometric optics model to explain the Nimbus-6 observations (X) and Hollinger (1971) (•) as a function of frequency. 


\section{REFERENCES}

Cardone, V. J., "Specification of the Wind Distribution in the Marine Boundary Layer for Wave Forecasting," Ph.D Thesis, New York University, Department of Meteorology and Oceanography, 1969 (Available from NTIS Order No. AD702490).

Chang, A. T. C., and T. T. Wilheit, "Remote Sensing of Atmospheric Water Vapor, Liquid Water, and Wind Speed at the Ocean Surface by Passive Microwave Techniques From the Nimbus-5 Satellite," NASA TM-79568, June 1978 submitted to Radio Science.

Cox, C. and Munk, W., "Some Problems in Optical Oceanography," J. Marine Res. $\underline{14}, 63-78$ (1955).

Hollinger, J. P., "Passive Microwave Measurements of Sea Surface Roughness," Trans. IEEE Geoscience Electronics, GE-9, pp 165-169 (1971).

Jackson, J. D., “Classical Electrodynamics,” John Wiley \& Sons, Inc., New York (1962), p $216 f f$.

Kline, L. A., and C. T. Swift, "An Improved Model for the Dielectric Constant of Sea Water at Microwave Frequencies," Trans. IEEE AP-25 104-1 11 (1977).

Lane, J. A. and J. A. Saxton, "Dielectric Dispersion in Pure Polar Liquids at Very High Radio Frequencies," Proc. Roy. Soc., London A, 214, pp 531-545, (1952).

Nordberg, W., J. Conaway, D. B. Ross, and T. Wilheit, "Measurements of Microwave Emission from a Foam-Covered Wind Driven Sea," J. Atmos. Sci., 38, 429-435 (1971).

Shutko, A., "Report on Soviet Progress in Microwave Radiometry of the Ocean's Surface," presented at IUCRM Colloquium on Passive Radiometry of the Ocean's Surface, Patricia Bay, B.C., Canada, June 1978.

Stogryn, A., "Equations for Calculating the Dielectric Constant of Saline Water," Trans. IEEE, MTT-19 733-736 (1971).

Webster, W. J., Jr., T. T. Wilheit, D. B. Ross, and P. Gloersen, "Spectral Characteristics of the Microwave Emission from a Wind Driven Foam-Covered Sea," J. Geophys. Res. $\underline{81}$, 3095-3099 (1976).

Wilheit, T. T., "The Effect of Wind on the Microwave Emission From the Ocean's Surface at $37 \mathrm{GHz}$," NASA TM-79588, July 1978 submitted to J. Geophys. Res. 